\title{
Treatment of cutaneous melanoma: current approaches and future prospects
}

This article was published in the following Dove Press journal:

Cancer Management and Research

16 August 2010

Number of times this article has been viewed

\author{
Alain P Algazi \\ Christopher W Soon ${ }^{2}$ \\ Adil I Daud' \\ 'Department of Medicine, Division \\ of Hematology and Oncology, \\ ${ }^{2}$ Department of Dermatology, \\ University of California, San Francisco \\ San Francisco, CA, USA
}

\begin{abstract}
Melanoma is the most aggressive and deadly type of skin cancer. Surgical resection with or without lymph node sampling is the standard of care for primary cutaneous melanoma. Adjuvant therapy decisions may be informed by careful consideration of prognostic factors. High-dose adjuvant interferon alpha- $2 \mathrm{~b}$ increases disease-free survival and may modestly improve overall survival. Less toxic alternatives for adjuvant therapy are currently under study. External beam radiation therapy is an option for nodal beds where the risk of local recurrence is very high. In-transit melanoma metastases may be treated locally with surgery, immunotherapy, radiation, or heated limb perfusion. For metastatic melanoma, the options include chemotherapy or immunotherapy; targeted anti-BRAF and anti-KIT therapy is under active investigation. Standard chemotherapy yields objective tumor responses in approximately $10 \%-20 \%$ of patients, and sustained remissions are uncommon. Immunotherapy with highdose interleukin-2 yields objective tumor responses in a minority of patients; however, some of these responses may be durable. Identification of activating mutations of BRAF, NRAS, c-KIT, and GNAQ in distinct clinical subtypes of melanoma suggest that these are molecularly distinct. Emerging data from clinical trials suggest that substantial improvements in the standard of care for melanoma may be possible.
\end{abstract}

Keywords: melanoma, resection, immune modulation, small molecule kinase inhibitors, chemotherapy, clinical trials

\section{Introduction}

Melanoma is an aggressive and often fatal type of cancer that arises from transformed melanocytes. These long-lived pigment-producing cells typically colonize the basal epidermis during embryonal development. The incidence of melanoma has been increasing at a steady rate over the last 8 decades: last year over 60,000 patients were diagnosed in the US and over 8,000 died from this disease. ${ }^{1}$ While the increase can be attributed in part to increased awareness and screening, there are indications that melanoma has become more common. Epidemiologic studies have shown association with a previous history of blistering sunburns, especially in childhood, and to a lesser extent with total ultraviolet exposure from all sources including tanning beds. The risk of developing melanoma is also increased in subjects who have many melanocytic nevi (moles), ie, benign proliferations of neoplastic melanocytes, and those with freckles and red hair, traits associated with germline polymorphisms in the melanocortin 1 receptor.

The clinical pathologic features of melanoma vary with the anatomic site in which it originates, which has led to the distinction of "histogenetic" subtypes of melanoma. ${ }^{2}$ Data from genetic analyses have confirmed the existence of distinct 
subtypes with characteristic genetic alterations depending on anatomic site and degree of sun-exposure. ${ }^{3,4}$ In addition to the skin, melanocytes are also present in leptomeninges, mucous membranes, and in the uvea of the eye and can occasionally give rise to melanoma. Unlike melanomas occurring on the sun-exposed skin, which are most common in Caucasians, melanomas arising from sites such as the palms and soles and nail beds (acral melanomas) and melanomas originating from mucous membranes of the oropharynx, nasopharynx or anogenital region or rectum (mucosal melanomas) show similar incidence in Asians, Africans, and Caucasians. In addition to their anatomic location in sun-protected sites which makes UV-radiation an unlikely etiologic factor, these two types also show distinct genetic features indicating that they are distinct categories. Uveal melanoma arises from melanocytes in the choroid, the iris, or the ciliary body and also has unique genetic and clinical features.

The management of melanoma depends greatly on the location, depth and stage at presentation. In this review, we describe current paradigms for the management of melanoma.

\section{Surgical excision of the primary cutaneous melanoma Wide local excision with I to $2 \mathrm{~cm}$ margins is the standard of care}

Surgical excision is the primary treatment for cutaneous melanoma. Optimal surgical margins depend on the thickness of the primary melanoma lesion. Three large trials examining excision margins for melanomas $2 \mathrm{~mm}$ or thinner in depth showed no significant difference in nodal recurrence, distant metastasis, disease-free survival, or overall survival after local excision when margins of $1 \mathrm{~cm}$ margins were compared to $3 \mathrm{~cm}$ margins ${ }^{5,6}$ or when $2 \mathrm{~cm}$ were compared to $5 \mathrm{~cm}$ margins. ${ }^{7,8}$ Similarly, a trial examining surgical margins for primary melanoma lesions of intermediate thickness ( 1 to $4 \mathrm{~mm}$ ) showed no significant difference in recurrence between patients undergoing excisions with 2 or $4 \mathrm{~cm}$ margins, but, significantly more patients in the $4 \mathrm{~cm}$ margin group required skin grafting ( $46 \%$ compared to $11 \%$ in the $2 \mathrm{~cm}$ margin group). In contrast, a British trial examining excision margins in melanomas greater than $2 \mathrm{~mm}$ thick demonstrated an increased rate of locoregional recurrence after excision with $1 \mathrm{~cm}$ margins in comparison with $3 \mathrm{~cm}$ margins. ${ }^{9}$ There are no large prospective randomized trials examining excision margins for thick melanomas (greater than $4 \mathrm{~mm}$ in thickness), but a retrospective study of 278 patients with melanomas greater than $4 \mathrm{~mm}$ thick showed that margins greater $2 \mathrm{~cm}$ did not improve the rates of local recurrence, disease-free survival, or overall survival. ${ }^{10}$ Based on these data, at our institution, we recommend $1 \mathrm{~cm}$ surgical margins for invasive melanomas $\leq 1.0 \mathrm{~mm}$ thick, 1 to $2 \mathrm{~cm}$ margins for melanomas between 1.01 and $2.0 \mathrm{~mm}$ in thickness, and $2 \mathrm{~cm}$ margins for melanomas thicker than $2.0 \mathrm{~mm}^{11}$

\section{Staging and risk stratification}

Once a melanoma has been excised, the pathologic characteristics of the lesion can be used for risk stratification. In addition, lymph nodes may also be available for evaluation. A primary goal of staging is to identify prognostic factors, which give insight into a given patient's expected clinical course, and potentially, predictive factors, which help to identify patients who are most likely to benefit from adjuvant therapy.

\section{Risk stratification based on tumor pathology}

The TNM staging system for node negative melanoma is based on survival data from more than 27,000 stage I and II melanoma patients. These data identified primary tumor thickness (also known as Breslow depth), ulceration, and a mitotic rate higher than $1 / \mathrm{mm}^{2}$ as factors associated with worse survival. ${ }^{12}$ For example, primary tumor thickness was a strong predictor of survival, and $92 \%$ of patients with node negative, $\mathrm{T} 1$ ( $<1 \mathrm{~mm}$ thick) melanoma primary tumors survived 10 years compared with only $50 \%$ of patients with node negative T4 ( $>4 \mathrm{~mm}$ thick) tumors. The new staging guidelines from the American Joint Committee on Cancer (AJCC) also identify primary tumor ulceration as an independent prognosticator of survival, ${ }^{12}$ and in a pooled meta-analysis of three large adjuvant interferon trials E1684, E1690, and E1694, primary tumor ulceration was associated with worse relapse-free survival $(\mathrm{RFS}, \mathrm{HR}=1.54)$ and overall survival (OS, HR $=1.73) \cdot{ }^{13}$ Interestingly, post-hoc analysis of two large European trials, EORTC 18952 and EORTC 18991, also suggested that patients with ulcerated primary lesions, particularly those with no more than minimal nodal metastases, may benefit more from treatment with adjuvant interferon than patients with non-ulcerated primary lesions. In these patients, interferon substantially decreased the risk of relapse by $25 \%$, the risk of developing distant metastasis by $31 \%$, and the risk of death by $31 \% .{ }^{14}$ These data have not been validated in a randomized, prospective trial. 
Indications for lymph node sampling in melanoma

Lymph node sampling is commonly used in melanoma patients to obtain additional prognostic data that may guide management decisions. In the absence of palpable regional lymphadenopathy, the decision to proceed with lymph node sampling after excision of a primary melanoma lesion is frequently based on the pretest probability of detecting nodal micro-metastatic disease, which increases monotonically with the depth of the primary lesion. In several large clinical trials and meta-analyses, nodal metastases were uncommon in patients with melanoma primary lesions under $1 \mathrm{~mm}$ thick, with positive nodes seen in only $1 \%-5.6 \%$ of patients. ${ }^{15,16}$ In contrast, thick lesions with Breslow depths greater than $4 \mathrm{~mm}$ were associated with high rates of nodal metastases with estimates ranging from $35.5 \%$ to $45 \% .^{15,16}$ Lesions of intermediate depth were associated with an intermediate probability of nodal metastasis. For example, in one study, the incidences nodal metastases in patients with 1-2 mm deep and 2-4 mm deep primary lesions were $15 \%$ and $30 \%$ respectively. ${ }^{17}$ Ulceration status, Clark's level, and regression have not been found to be useful in predicting sentinel lymph node status.

The sentinel lymph node biopsy procedure was developed as a means of identifying patients with nodal metastasis without the morbidity associated with a complete lymph node dissection, and the presence and size of metastases in the sentinel lymph nodes are have substantial prognostic value. In a sentinel lymph node biopsy, a radioisotope, Tc99 colloid, and blue dye are injected circumferentially around the primary melanoma site, and the location of the sentinel lymph node is determined using a lymphoscintigram, a handheld Geiger counter, visual inspection, and confirmatory pathological analysis. ${ }^{18}$ Patients with negative sentinel lymph node biopsies rarely have evidence of metastatic melanoma in non-sentinel nodes (incidence $\leq 1 \%$ ). ${ }^{18,19}$ Furthermore, patients undergoing sentinel lymph node biopsy only have a much lower incidence of surgical complications, including lymphedema, wound infection, and hematoma/ seroma formation, than patients undergoing complete regional lymph node dissections. ${ }^{20}$ In general, the presence of nodal melanoma metastases confers a worse overall prognosis. For example, in a randomized trial of 1347 patients with primary melanomas either $\geq 1 \mathrm{~mm}$ thick or with a high Clark level (IV or V), positive sentinel node biopsies conferred significantly worse rates of 5-year disease-free (53.4\% compared to $83.2 \%$ for sentinel node negative patients) and melanoma-specific survival (72.3\% compared to $90.2 \%) .{ }^{21} \mathrm{~A}$ recent retrospective analysis suggested that the size of nodal metastatic foci is associated with overall prognosis. Specifically, 5-year melanoma-specific survival rates decreased monotonically with increasing size of the largest nodal metastatic focus in the sentinel lymph node (MSS $=94 \%$ for metastases $<0.1 \mathrm{~mm}, 70 \%$ for $0.1-1.0 \mathrm{~mm}$, and $57 \%$ for $>1.0 \mathrm{~mm} ; P<0.001)$. Furthermore, only $9 \%$ of patients with minimal sentinel node disease (largest focus $<0.1 \mathrm{~mm}$ ) developed distant metastases at 5 years follow-up..$^{22}$ These data suggest that patients with minimal sentinel node disease may require neither completion lymphadenectomy or adjuvant systemic therapy. However, these data have yet to be validated prospectively, and the revised TNM staging criteria established by the American Joint Committee on Cancer state that miniscule foci of nodal melanoma metastases detected by immunohistochemistry represent node positivity and warrant a designation of stage III disease. ${ }^{12}$

A completion lymph node dissection, radical dissection of the remaining regional lymph nodes, is typically recommended for further risk stratification after a positive sentinel lymph node finding, but the therapeutic benefit of this procedure is controversial. ${ }^{12}$ Several large clinical trials have failed to demonstrate any improvement in melanoma specific survival ${ }^{21}$ or overall survival in patients undergoing complete lymph node dissections. ${ }^{23-27}$ The Multicenter Sentinel Lymphadenectomy Trial (MSLT) did show a significant difference in disease-free survival $(78.3 \%$ vs $73.1 \%$ at 5 years), and a post-hoc analysis demonstrated improved survival in sentinel lymph node-positive patients who underwent immediate lymphadenectomy compared to patients who received delayed lymphadenectomy for palpable nodal metastasis in the observation group (5-year OS $72.3 \%$ vs $52.4 \%$ ). However, these post-randomization subgroups are not equivalent since all patients who received delayed lymphadenectomy had developed palpable nodal disease whereas only a subset of patients of patients with initially microscopic nodal disease would be anticipated to develop palpable nodal metastases in the future. Based on these data, we recommend completion lymph node dissection when findings of the procedure will guide adjuvant therapy decisions or when recurrence is likely to cause physical or psychological morbidity.

\section{The role of imaging in staging}

The identification distant metastases in patients with primary melanoma lesions significantly impacts management since the management and prognosis of systemic melanoma differs substantially from that of local or locoregional 
disease. However, based on the pre-test probability of finding metastatic lesions, whole body imaging with a CT or $\mathrm{PET} / \mathrm{CT}$ scan is appropriate only for patients with regional nodal metastases. CT imaging detects occult disease in $0.5 \%-3.7 \%$ of patients ${ }^{28-31}$ with microscopic nodal metastases on sentinel lymph node biopsy and in $4 \%-16 \%$ of patients with clinically palpable nodal disease. ${ }^{31-34}$ In contrast, only one true metastatic lesion was identified in a total of over 500 patients with invasive, node-negative melanoma evaluated in two large studies. ${ }^{35,36}$ Thus, available data do not support the routine use of imaging in initial staging of clinically nodenegative melanoma.

\section{Adjuvant (post-operative) therapy for high risk melanoma Radiation therapy}

External beam radiation is most commonly used in patients with resected nodal metastases to prevent local recurrence in the irradiated nodal basin. A recent randomized trial examined a total external beam radiation dose of 48 Gy in 20 daily fractions versus no treatment in 248 patients with resected, high-risk, node-positive melanoma. Radiation therapy decreased the incidence of in-field relapse (35\% vs $18 \%, P<0.005)$ without impacting the incidence of distant metastases. There was also a concerning trend toward decreased overall survival in patients treated with radiation compared with patients randomized to observation (overall survival 2.6 vs 3.9 years). ${ }^{37}$ Thus, external beam radiation may be most appropriate when local recurrence would be associated with a high degree of morbidity.

\section{Interferon alpha-2b}

Treatment with high doses of adjuvant interferon in high-risk stage II and stage III melanoma reduced the risk or disease recurrence and increased the median disease-free survival in several large trials. The ECOG trial E1684 (1996) established a high dose interferon regimen that remains the standard of care today for adjuvant therapy in high risk stage II and stage III melanoma. ${ }^{38}$ In the trial, patients randomized to the interferon arm received doses of 20 $\mathrm{MIU} / \mathrm{m}^{2} /$ day intravenously for 1 month then $10 \mathrm{MIU} / \mathrm{m}^{2}$ 3 times per week subcutaneously for 48 weeks. Adjuvant interferon increased the median relapse-free survival from 1 to 1.7 years $(P=0.0023$, one-sided $)$ and overall survival from 2.8 to 3.8 years $(P=0.0237$, one-sided) compared with observation. Common grade 3 and 4 toxicities included bone marrow suppression, hepatotoxicity, fatigue, flu-like symptoms, and neuropsychiatric disturbances. However, while dose modifications were necessary in the majority of patients, most patients were able to tolerate $80 \%$ or more or the scheduled dose. Several trials have demonstrated improvements in relapse-free survival using lower doses of interferon, ${ }^{39-41}$ but such doses appear to be less effective. In one head-to-head comparison, the E1694 regimen significantly increased the rate of 5-year relapse-free survival versus placebo ( $44 \%$ vs $35 \%, P=0.05$ ) while low-dose interferon, 3 MIU subcutaneously daily 3 times per week, did not (5-year relapse-free survival $40 \%$ vs $35 \%, P=0.17$ ). ${ }^{42}$ A meta-analysis of several trials, including ECOG trials E1684, E1690, and E1694, also demonstrated that high-dose interferon regimens increase the duration of relapse-free survival, but adjuvant interferon conferred only a small overall survival benefit in this meta-analysis. ${ }^{13}$

Several trials have examined the optimal duration of adjuvant interferon therapy. The Hellenic Cooperative Oncology Group compared a 4-week intravenous interferon regimen with and without 48 weeks of subsequent subcutaneous interferon and demonstrated no significant difference in the relapse-free survival between the two treatment groups. ${ }^{43}$ Furthermore, it was noted that the patients treated for only 4 weeks were less likely to suffer significant adverse effects including hepatotoxicity, nausea/vomiting, alopecia, and neurologic toxicity. However, this study has been criticized since the interferon doses used in the 1-year comparison arm were substantially lower than those used in E1684. Since the efficacy of adjuvant interferon appears to be dose-dependent, it is possible that this trial compared two ineffective regimens. A trial of 4 weeks of high-dose adjuvant interferon versus placebo in patients with high risk melanoma is currently ongoing. ${ }^{44}$ Other studies have examined extended interferon regimens with treatment durations of 2-5 years, but none have used the standard-ofcare E1684 regimen as a comparator. For example, EORTC trial 18952 used interferon doses that were 50\%-75\% less than those used in E1684. With these lower doses, 25 months of therapy appeared to be superior to 13 months, with a larger decrease in the risk of developing distant metastasis (7.2\% vs 3.2\%) and a modest survival benefit with the longer regimen. ${ }^{39}$ Extended courses of pegylated interferon also appear to be effective. EORTC trial 18991 demonstrated an improved rate of relapse-free survival in patients receiving a 5-year course of pegylated interferon versus controls ( 45.6 vs $38.9 \%, P=0.01) .{ }^{45}$ There was no significant difference in distant metastasis-free survival or overall survival between the two groups. 


\section{GM-CSF}

Recent studies suggest that adjuvant treatment with granulocyte-macrophage colony stimulating factor (GMCSF or sargramostim) may also reduce the risk of melanoma recurrence in patients with resected disease with less toxicity than interferon alpha-2b. GM-CSF is a hematopoetic growth factor that also modulates immune system activity in a variety of ways, mediating the proliferation and maturation of antigen-presenting dendritic cells ${ }^{46,47}$ and activating monocytes and macrophages. ${ }^{48,49}$ Spitler and colleagues tested a 3-year course of adjuvant GM-CSF in 98 patients with resected stage II(T4), III, or IV melanoma. The median, melanoma specific survival rate at 5 years in this cohort was $60 \%$ overall and $67 \%$ and $40 \%$ for patients with resected stage III and resected stage IV disease respectively. ${ }^{50}$ The overall 5-year disease-free survival rate was $36 \%$. In another trial at the Moffitt Cancer Center, 39 patients with resected stage IIIB, IIIC, or IV melanoma were treated with GM-CSF for 1 year with a median overall survival of 65 months and a median disease-free survival of 5.6 months. ${ }^{51} \mathrm{An}$ increase in the number of mature dendritic cells in the peripheral blood was associated with remission or delayed recurrence. Based on these and other experimental data, the ongoing ECOG trial E4697 is comparing a 1-year course of GM-CSF, with or without melanoma-antigen peptide vaccination, to placebo in patients with high-risk node positive, recurrent, and completely resected metastatic melanoma. ${ }^{52}$ As of September of 2009, data from 735 patients were available, and patients treated with GM-CSF had a significantly longer DFS (11.8 months) than patients not receiving GM-CSF (PFS 8.8 months, $P<0.05){ }^{53}$

\section{Other systemic adjuvant therapies}

Melanoma is thought to be an immunogenic tumor, and a number of additional approaches toward boosting antitumor immunogenicity have been tested in the adjuvant setting. Thus far, adjuvant trials of tumor vaccines derived from melanoma cells, ${ }^{54,55}$ cell lysates,${ }^{56}$ and melanoma antigens including GM2 ganglioside, ${ }^{57}$ tyrosinase, gp-100, and MART- $1^{52}$ have failed to improve disease-free or overall survival in patients with resected melanoma. Ipilimumab is an anti-CTLA4 antibody designed to disinhibit antitumor immune responses with the goal of breaking the immune system's tolerance to melanoma antigens. A phase II trial examined a 12-month course of ipilimumab with or without a multipeptide vaccine in patients with resected stage III and stage IV melanoma. At a median of 23 months follow-up, $64 \%$ remained disease-free and only $9.3 \%$ of patients had died. ${ }^{58,59} \mathrm{~A}$ randomized phase 3 trial comparing adjuvant ipilimumab to placebo after resection of high-risk stage III melanoma is currently ongoing. ${ }^{60}$ Biochemotherapy, a combination of multiple cytotoxic chemotherapy agents with immune modulators, was developed to overcome the relative treatment resistance of metastatic melanoma. A randomized phase III trial compared year-long high or intermediate dose adjuvant interferon regimens with 4 cycles of an adjuvant biochemotherapy regimen consisting of cisplatin, vinblastine, dacarbazine, interferon, and interleukin-2. ${ }^{61}$ There were no significant differences between the interferon and biochemotherapy groups with respect to median relapse-free or overall survival, but biochemotherapy was substantially more toxic then either interferon regimen. The trial was stopped due to futility after an interim analysis.

\section{Treatment of loco-regionally advanced and in-transit disease}

While local excision of isolated in-transit metastases is often feasible in patients with melanoma, more widespread regional cutaneous disease (Figure 1) may not be amenable to this approach. Several non-surgical modalities including localized immune therapy, heated limb perfusion, and external beam radiation appear to confer reasonable rates of regional disease control in this setting.

\section{Localized immune therapy}

Localized administration of immune modulating agents has been shown to lead to regression of cutaneous melanoma metastases in several phase II studies. In one study, intralesional interleukin-2 given 2-3 times weekly was tested in 24 patients with one or more soft tissue or cutaneous melanoma metastases yielding complete responses in $65 \%$

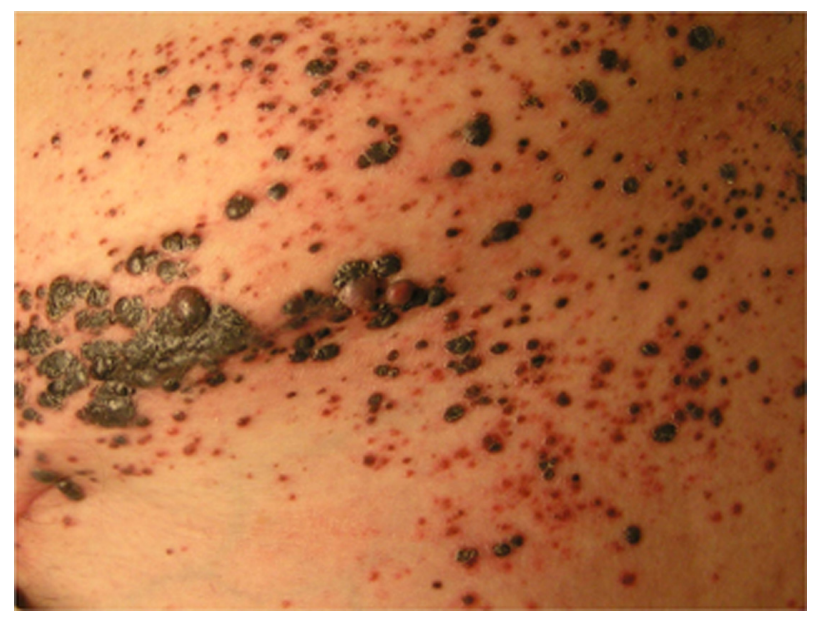

Figure I Unresectable melanoma in-transit metastases. 
of patients and partial responses in $21 \% .^{62}$ Recurrence of completely-regressed lesions was not observed, but the subsequent development of visceral metastases was common, occurring in 9 of 16 treated patients with stage III disease. Common and significant adverse events included pain at the injection site, local inflammation at the injection site, fever, flu-like symptoms, fatigue, nausea and vomiting. Intralesional interleukin-2 has also been given in combination with imiquimod, an agonist of toll-like receptor 7 , with complete regression of $40.7 \%$ of 182 lesions treated, including cutaneous and subcutaneous lesions, and partial regression of $9.8 \%{ }^{63}$

Gene-based immunotherapy with electroporation is a novel approach to treating patients with cutaneous melanoma metastases. In a phase I dose escalation study, a plasmid bearing DNA for IL-12, was injected into cutaneous melanoma lesions in 24 patients with stage III or IV disease. The injected lesions were then treated immediately with electroporation using a circular array of electrodes. ${ }^{64}$ This procedure was repeated on treatment days 1, 5, and 8. Intratumoral IL-12 expression assessed by enzyme-linked immunosorbant assay (ELISA) increased with increased plasmid dose, and no significant systemic toxicities were noted even at the highest plasmid dose tested. Nineteen of the 24 patients had distant metastases not treated with the plasmid or electroporation. Of this subgroup, two had complete responses with regression of untreated lesions, and an additional patient achieved a CR after completion of electroporation and treatment with dacarbazine. Seven additional patients had stabilization of systemic disease after treatment. These results suggest that intratumoral electroporation of plasmid DNA encoding IL-12 could lead to systemic antitumor immune responses with minimal systemic toxicity. Further studies of this treatment regimen are planned.

\section{Isolated limb perfusion}

Isolated limb perfusion is a therapeutic option for the local management of cutaneous melanoma metastases isolated to one extremity. In this procedure, the major vascular structures are isolated, cannulated, and then attached to a bypass device so that therapeutic agents can be given to the extremity at doses that would be too high to tolerate if given systemically. ${ }^{65}$ In several retrospective studies, isolated limb perfusion using interferon, melphalan and TNF-alpha alone or in combination suggest complete response rates ranging from $26 \%$ to $69 \%$ with partial responses in an additional 25\%-43\%. ${ }^{66-68}$ Responses appear to be transient with estimates of response duration and progression-free survival ranging from 9 to 12.4 months. ${ }^{66,67}$
Long-term toxicities associated with isolated limb perfusion include lymphedema, abnormal limb function, muscle atrophy or fibrosis, neuropathy, persistent pain, and recurrent infection. ${ }^{69}$ Thus, isolated limb perfusion may be an option for patients with in-transit limb metastases, but there are significant toxicities.

\section{External beam radiation}

External beam radiation with hyperthermia provides an additional therapeutic option for patients with unresectable melanoma in-transit metastases. A 1995 prospective, randomized trial examined external beam radiation in 70 patients with cutaneous, subcutaneous, or nodal melanoma. The 2-year local control rates for radiation with and without hyperthermia were $46 \%$ and $28 \%$ respectively $(P<0.05$ based on univariate analysis $){ }^{70,71}$

\section{Systemic disease}

Objective tumor responses are achieved only in a small minority of patients using standard-of-care therapies, and durable responses are uncommon. In addition, a recent metaanalysis of over 2000 patients enrolled in phase II clinical trials found a median overall survival of 6.2 months. ${ }^{72}$ New, rationally based treatment approaches are currently under study, and options for enrollment in clinical trials should be presented to all patients with metastatic melanoma.

\section{Limited stage IV disease \\ Surgical resection}

There are several small case series describing patients with a limited extent of metastatic melanoma who had a relatively extended period of survival after resection of these tumors. In retrospective studies of highly selected patients, resection of isolated melanoma metastases in the liver and lung yielded median postoperative overall survival durations of 19-28 months, ${ }^{73-75}$ which compare favorably to historical survival data for a general melanoma population. However, it is not clear whether lead time bias, selection bias, or surgical intervention was the primary determinant of survival in many of these studies. Adjuvant GM-CSF has been studied in patients with resected, stage IV disease as described in the adjuvant therapy section of this review.

\section{Immunotherapy for metastatic disease} Interleukin-2

Interleukin-2 is a potent immune modulator that stimulates activation and proliferation of $\mathrm{T}$ lymphocytes. Treatment with high-dose interleukin-2 leads to objective tumor responses 
in a minority of patients, but a subset of reported complete responses have been durable. Overlapping, non-randomized trials, retrospective case series and meta-analyses of 100 or more patients with metastatic melanoma treated with highdose interleukin- 2 have reported PR rates of $8.2 \%-10 \%$ and CR rates of $6 \%-6.6 \%{ }^{76-79}$ Sustained CRs have been reported in $4.4 \%-5.5 \%$ of patients. ${ }^{78,79}$ Patients with melanoma limited to subcutaneous tissue and those receiving more interleukin-2 doses are more likely to have objective tumor responses. ${ }^{80}$ Treatment with high-dose interleukin-2 typically is reserved for younger, fitter patients, and it requires intensive monitoring. High-dose interleukin-2 therapy is associated with substantial toxicity including hypotension, oliguria, renal insufficiency, hepatocellular damage, edema, respiratory compromise, fevers, chills, pruritis, diarrhea, myocardial infarction, sepsis, and death.

\section{Interleukin-2 with peptide vaccination}

Recent data suggest that vaccination against the melanoma peptide antigen gp-100 may improve the efficacy of high dose interleukin-2. Preliminary reports from a randomized, multicenter phase III trial found a higher overall response rate in patients receiving interleukin-2 with a gp-100 peptide vaccine in comparison with patients receiving interleukin-2 alone (overall response rate $=22.1 \%$ vs $9.7 \%, P<0.05$ ).${ }^{81}$ Notably, the rate of response to interleukin-2 alone is considerably lower than the overall response rate of approximately $16 \%$ reported in previous studies, ${ }^{76-79}$ and a 2008 metaanalysis of 3 phase II trials examining this interleukin-2 vaccine combination reported an overall response rate of $16 \%$ in 121 patients treated. ${ }^{82} \mathrm{~A}$ blinded review of the phase III response data was pending at the time these data were presented.

\section{Anti-CTLA4 antibodies}

The use of anti-CTLA4 antibodies in patients with advanced melanoma has emerged as a novel strategy for eliciting effective antitumor immune responses. Antigen presenting cells in the human immune system present antigen fragments on major histocompatibility complexes, and a second surface protein, B7, acts as a costimulatory molecule for T lymphocytes. The T-cell surface protein, CTLA4, competes with CD28 for B7, and binding of CTLA4 to B7 inhibits T-cell proliferation and the elaboration of immune stimulatory cytokines. Thus anti-CTLA4 antibodies have been developed to abrogate these inhibitory interactions, favoring immune stimulation and in principle, breaking immune tolerance to melanoma. ${ }^{83}$
Clinical trials of the anti-CTLA4 ipilimumab in advanced melanoma have led to modest rates of objective tumor responses, but, thus far, registration trials of ipilimumab have failed to meet clinical end points required for the drug to be approved by the United States Food and Drug Administration. Response rates to ipilimumab appear to be dose dependent. For example, in one trial, the objective response rate in patients receiving ipilimumab at doses of $0.3 \mathrm{mg} / \mathrm{kg}, 3 \mathrm{mg} / \mathrm{kg}$, or $10 \mathrm{mg} / \mathrm{kg}$ were $0 \%, 4 \%$ and $11 \%$ respectively ${ }^{84}$ and higher doses were also associated with increased rates of prolonged stabilization of disease. A phase II registration trial of an ipilimumab regimen consisting of $10 \mathrm{mg} / \mathrm{kg}$ doses every 3 weeks for 4 doses followed by maintenance infusions every 12 weeks was tested in 150 patients and yielded an overall response rate of $5.8 \%$ with stabiliation of disease in an additional $21.3 \% .{ }^{85} \mathrm{~A}$ recent meta-analysis of 3 phase II studies of ipilimumab, CA184-008, CA184-022, and CA184-007, examined overall survival in a pretreated population. ${ }^{86} \mathrm{~A}$ total of 487 patients were enrolled in the 3 trials and of those receiving $10 \mathrm{mg} / \mathrm{kg}$ doses of ipilimumab every 3 weeks for 4 doses followed by maintenance infusions every 12 weeks, the median overall survival was greater than 10 months. Common toxicities observed with ipilimumab included grade 3 and 4 immune-related adverse events such as colitis, dermatitis, uveitis, enterocolitis, hepatitis, and hypophysitis. The incidence of immune-related adverse events has been correlated with clinical response. ${ }^{58,87,88}$ Latent responses to ipilimumab have been described, and it has been proposed that early evaluation of patients treated with this agent using RECIST criteria may not predict long-term clinical benefit from the drug. ${ }^{89}$ For example, in one study, 7 of 26 patients continued on ipilimumab despite progression of disease by RECIST criteria had latent tumor responses by a novel set of criteria deemed the immune-related response criteria. ${ }^{90}$

Ipilimumab has also been evaluated in combination with melanoma tumor vaccines, chemotherapeutics, and immune modulating agents. Based on data to date, the addition of peptide vaccination to ipilimumab does not appear to improve response rates or survival. ${ }^{87,91}$ Recently, results were reported for a phase III trial comparing the safety and efficacy of the ipilimumab with or without gp-100 peptide vaccine versus gp-100 alone in patients with unresectable stage III or IV melanoma who had previously progressed on treatment regimens containing either dacarbazine, temozomide, fotemustine, carboplatin, or IL-2. Median overall survival was significantly improved in the group receiving ipilimumab alone versus gp-100 alone (10.1 vs 6.6 months).There was no difference in overall 
survival when comparing the group receiving ipilimumab alone versus ipilimumab plus gp-100 (10.1 vs 10.0 months).$^{92}$ Initial reports suggest that combinations of ipilimumab with chemotherapy warrant further investigation. A randomized phase 2 trial of ipilimumab with or without dacarbazine found objective responses in $5.4 \%$ of patients treated with ipilimumab alone versus $17.2 \%$ of patients treated with ipilimumab in combination with dacarbazine. ${ }^{93,94}$ Clinical benefit rates ( $\left.\mathrm{CR}+\mathrm{PR}+\mathrm{SD}\right)$ were $16.2 \%$ and $28.6 \%$ in patients treated without and with dacarbazine respectively. A large phase 3 trial is currently under way to assess the efficacy of dacarbazine with and without ipilimumab. ${ }^{95}$ Ipilimumab has also been combined with high-dose interleukin-2 with an objective response rate of $22 \%$ in 36 patients treated. ${ }^{96}$

\section{Adoptive cell transfer}

Adoptive cell transfer is a technique in which melanoma reactive lymphocytes are identified and expanded ex vivo and then re-infused into a patient in an effort to enhance antitumor immunity. Early trials examining this approach yielded high rates of initial objective tumor responses, but these responses were transient and infused tumor-infiltrating lymphocytes did not persist in the peripheral blood in significant titer. ${ }^{97,98}$ Subsequent trials utilized lymphocyte depletion prior to infusion of tumor infiltrating lymphocytes in order to reduce the mitigating effects of regulatory T-cells and to decrease competition for homeostatic cytokines. ${ }^{99}$ In a recent iteration of this approach, 93 patients were treated with a non-myeloablative preparatory regimen comprised of cyclophosphamide $60 \mathrm{mg} / \mathrm{kg}$ daily for 2 days followed by fludarabine dosed at $25 \mathrm{mg} / \mathrm{m}^{2}$ daily for 5 days. ${ }^{100}$ Subgroups of patients were also treated with either 2 Gy or 12 Gy of total body irradiation (TBI). 49\% of unirradiated patients had objective tumor responses by RECIST criteria compared with $52 \%$ of patients receiving 2 Gy of TBI and $72 \%$ of patients treated with 12 Gy. Tumor regressions at visceral sites and in the brain were observed. Unlike in previous trials, the expanded tumor-infiltrating lymphocyte clone was frequently detectable, often at high levels, in the peripheral blood months after the infusion, and such persistence was associated with tumor regression. It has been suggested that since tumor infiltrating lymphocytes can only be expanded in about half of patients, ${ }^{101}$ objective tumor response rates by intention to treat analysis would be $50 \%$ lower than the response rates reported above. Several trials of adoptive cell transfer in melanoma are currently accruing, including studies using tumor infiltrating lymphocytes, ${ }^{102,103}$ and a trial evaluating the antitumor efficacy of T-cells modified ex vivo to express the melanoma antigen MART-1. ${ }^{104}$

\section{Chemotherapy for metastatic disease}

Several cytotoxic chemotherapy agents have been shown to yield objective tumor responses or prolonged stabilization of disease in advanced melanoma, but none has been proven to improve overall survival over best supportive care. The alkylating agent dacarbazine is the only cytotoxic agent approved by the FDA for the treatment of metastatic melanoma, with reported objective response rates ranging from $5.5 \%$ to $20 \%{ }^{105-109}$ Sustained complete responses have been described in $1 \%-2 \%$ of patients treated with dacarbazine. ${ }^{110}$ Dacarbazine-based combination chemotherapy regimens, including cisplatin/vinblastine/dacarbazine ${ }^{111,112}$ and cisplatin/dacarbazine/BCNU/tamoxifen, ${ }^{106}$ generally confer increased toxicity without improvements in progression-free or overall survival compared with dacarbazine alone. Temozolomide is an orally bioavailable analog of dacarbazine with good central nervous system penetration that was compared head-to-head with dacarbazine in a phase III clinical trial yielding an overall response rate of $13.5 \%$ versus $12.1 \%$ for dacarbazine. ${ }^{107}$ There were no differences between the two agents with respect to progression-free or overall survival, but a subsequent retrospective analysis did demonstrate fewer relapses in the central nervous system in patients treated with temozolomide. ${ }^{113}$

Alternatives to dacarbazine also include paclitaxel, a microtubule stabilizing agent, often with carboplatin. Phase II trials of paclitaxel monotherapy in chemotherapy naïve patients yielded objective response rates ranging from $0 \%$ to $16.4 \%,{ }^{114-116}$ and second-line trials of carboplatin with paclitaxel yield objective responses in $11 \%-36 \% .{ }^{117}$ Taxanes, such as paclitaxel, have poor penetration into the central nervous system ${ }^{118}$ limiting their utility in patients with melanoma brain metastases, and they are susceptible to chemotherapy resistance mechanisms such as over-expression of the multidrug resistance-1 drug transporter. ${ }^{119}$ Sagopilone is a fully-synthetic, third generation epothilone that evades the multidrug resistance-1 efflux pump ${ }^{120,121}$ and crosses the blood-brain barrier. Sagopilone has antitumor efficacy in a xenograft model of melanoma brain metastases ${ }^{122}$ and in clinical trials in patients with malignant glioma. ${ }^{123,124} \mathrm{~A}$ recent single-arm phase II trial of sagopilone in 35 patients with unresectable stage III and stage IV melanoma demonstrated one CR and three PRs in addition to stabilization of disease in eight additional patients. ${ }^{125}$ 
Biochemotherapy was developed in an effort to overcome treatment resistance in metastatic melanoma. Biochemotherapy, often combining cisplatin,vinblastine, dacarbazine, interferon, and interleukin-2, has been evaluated in metastatic melanoma in two phase III clinical trials ${ }^{126,127}$ and a meta-analysis of 18 randomized trials involving 2621 patients. ${ }^{128}$ While initial response rates were high (19.5\%-33\%), no study has documented significant survival benefits in comparison with conventional chemotherapy. One recent phase II study in 133 chemotherapy-naive patients with metastatic melanoma was designed to address the transience of responses to biochemotherapy by adding maintenance interleukin-2 to 4 cycles of biochemotherapy. As seen in prior studies, the initial overall response rate to biochemotherapy was high with complete responses in $8 \%$ of patients and partial responses in $36 \%$ of patients. ${ }^{129}$ However, responses were again transient with a median progression-free survival was 9 months and the median overall survival was 13.5 months.

\section{Targeted therapy}

Several oncogenic mutations have been identified in cutaneous melanoma that may drive the malignant phenotype

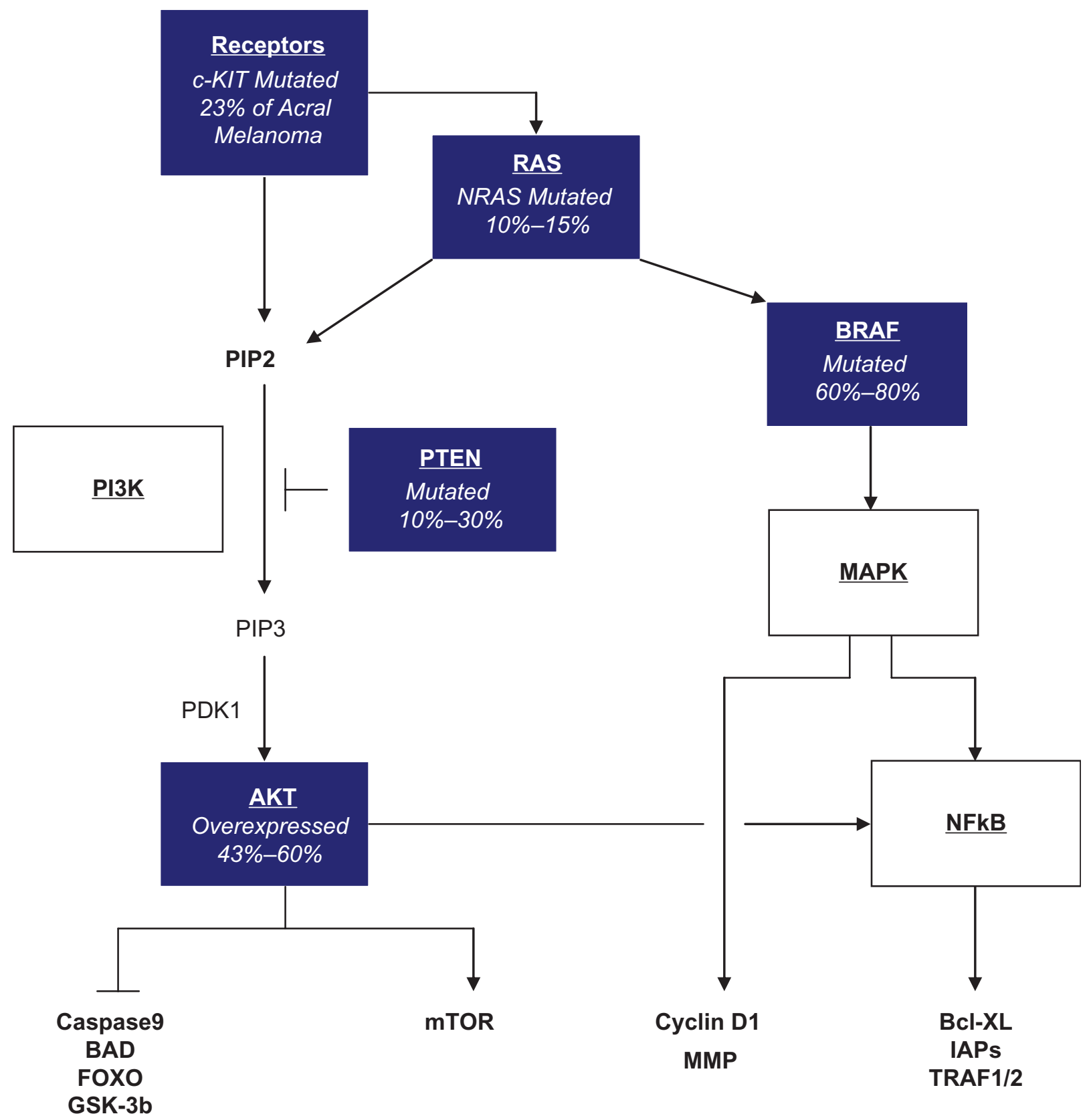

Figure 2 Common activating mutations in melanoma. 
by altering downstream signaling through the PI3K/AKT/ mTOR and MAP kinase pathways to decrease apoptosis ${ }^{130}$ and increase cell cycling. ${ }^{131}$ Known oncogenic mutations in melanoma include NRAS mutations, found in $10 \%-15 \%$ of melanomas, loss of PTEN, observed in $10 \%-30 \%,{ }^{130} \mathrm{c}-\mathrm{KIT}$ mutations seen in $23 \%$ of acral melanomas, ${ }^{132}$ and activating BRAF mutations, seen in $60 \%-80 \%$ of cutaneous melanoma tumors (see Figure 2). Several agents targeting these molecular aberrations, including drugs targeting the c-KIT and $\mathrm{BRAF}^{\mathrm{V} 600 \mathrm{E}}$ mutations, are currently being evaluated in clinical trials.

\section{Targeting the BRAF ${ }^{\mathrm{V} 600 \mathrm{E}}$ mutation}

Efforts to target the BRAF ${ }^{\mathrm{V} 600 \mathrm{E}}$ mutation have now led to the development of a highly selective BRAF inhibitor that has shown tremendous promise in early clinical trials. Initial trials of RAF inhibitors in melanoma focused on sorafenib, a multi-kinase inhibitor targeting RAF, VEGF, and PDGF receptor tyrosine kinase signaling. ${ }^{133}$ However, a phase III trial comparing carboplatin and paclitaxel with and without sorafenib showed no differences between the two treatment groups with respect to the rate of objective tumor response, progression-free survival, and overall survival. ${ }^{117}$ PLX4032 is a novel tyrosine kinase inhibitor engineered to have a high degree of specificity for mutant $B \mathrm{RAF}^{\mathrm{V} 600 \mathrm{E}}$. A phase I clinical trial presented at the 2009 Annual Meeting of the American Society of Clinical Oncology (ASCO) showed tumor regressions in 5 of 7 known $\mathrm{BRAF}^{\mathrm{V} 600 \mathrm{E}}$ positive melanoma patients treated at doses of at least $240 \mathrm{mg}$ orally twice daily. ${ }^{134}$ In a separate presentation, this dose level was also determined to be minimum dose required for $90 \%$ inhibition of BRAF signaling as assayed using immunohistochemistry for phospho-ERK protein levels. ${ }^{135}$ An open-label phase II trial of PLX-4032 in patients with previously treated melanoma has recently completed accrual ${ }^{136}$ and a randomized phase III trial comparing single agent PLX-4032 with dacarbazine in the first-line setting is currently opening nationwide. ${ }^{137}$

\section{Targeting c-KIT mutant melanoma}

In a retrospective analysis of biopsy specimens from 189 melanoma lesions, mutations of c-KIT exons 11, 13, and 17 were observed in $1.7 \%$ of cutaneous melanomas, $23 \%$ of acral melanomas, and $15.6 \%$ of mucosal melanomas. ${ }^{132}$ Several small-molecule tyrosine kinase inhibitors that are approved by the FDA for other indications target c-KIT including sunitinib, imatinib, nilotinib, and dasatinib. Imatinib does not appear to be effective in an unselected population of patients with metastatic melanoma. ${ }^{138}$ However, in preliminary results from an ongoing phase II trial restricted to patients with tumors harboring somatic c-KIT mutations, imatinib dosed at $400 \mathrm{mg}$ twice daily induced partial tumor responses in three of five patients and the remaining two patients achieved prolonged stabilization of disease. ${ }^{139}$ Most patients required dose reductions for significant toxicities including gastrointestinal symptoms, rash, fatigue, and visual changes. In addition to the phase II imatinib trial, a case report describes 70\% tumor shrinkage after treatment with sunitinib in a patient with metastatic mucosal melanoma bearing a mutation in KIT exon $11 .{ }^{140}$ In a recent report, the c-KIT mutation L576P was associated with resistance to multiple KIT inhibitors including imatinib, nilotinib, and sorafenib, but objective tumor responses could be induced in 2 patients bearing the KIT L576P mutation after treatment with dasatinib. ${ }^{141}$ Currently, 6 separate trials are testing c-KIT inhibitors in patients with melanoma arising from chronically sun-damaged skin, acral melanoma, mucosal melanoma, or documented c-KIT mutant melanoma. ${ }^{142-147}$

\section{Central nervous system metastases Radiation therapy for melanoma brain metastases}

Brain metastases are a common cause of morbidity and mortality in patients with metastatic melanoma and radiation therapy is the mainstay of treatment for patients with melanoma brain metastases. Whole brain radiation therapy for melanoma brain metastases appears to confer overall survival benefits in comparison with best supportive care. Based on retrospective data, patients with melanoma brain metastases treated with whole brain radiation therapy survived 1 month longer than those undergoing observation only (overall survival 3.4 vs 2.1 months). ${ }^{148}$ Latent toxicities associated with whole brain irradiation include cognitive deficits, cerebrovascular disease, neuroendocrine dysfunction, and normal pressure hydrocephalus. Compared whole brain irradiation, stereotactic radiosurgery is associated with less post-procedural morbidity. However, retrospective analyses examining the effect of stereotactic radiosurgery may be prone to lead time bias, patient selection bias or other factors. Such studies found overall survival durations for patients with melanoma brain metastases treated with stereotactic radiosurgery ranging from 6 to 7.5 months. ${ }^{149-152}$ One retrospective study that stratified for differences in age, number of brain lesions, and the presence of symptoms prior to treatment found a survival benefit of 7.3 months $(P=0.05)$ associated with gamma knife radiosurgery or surgical 
excision when combined with whole brain irradiation in comparison to whole brain irradiation alone. ${ }^{153}$

\section{Disclosure}

The authors report no conflicts of interest in this work.

\section{References}

1. Jemal A, Siegel R, Ward E, et al. Cancer Statistics, 2008. CA Cancer J Clin. 2008;58(2):71-96.

2. Linos E, Swetter SM, Cockburn mg, Colditz GA, Clarke CA. Increasing burden of melanoma in the United States. J Invest Dermatol. 2009;129(7):1666-1674.

3. McGovern VJ, Cochran AJ, Van der Esch EP, Little JH, MacLennan R. The classification of malignant melanoma, its histological reporting and registration: a revision of the 1972 Sydney classification. Pathology. 1986;18(1):12-21.

4. Curtin JA, Fridlyand J, Kageshita T, et al. Distinct sets of genetic alterations in melanoma. $N$ Engl J Med. 2005;353(20):2135-2147.

5. Veronesi U, Cascinelli N, Adamus J, et al. Thin stage I primary cutaneous malignant melanoma. Comparison of excision with margins of 1 or $3 \mathrm{~cm}$. N Engl J Med. 1988;318(18):1159-1162.

6. Veronesi U, Cascinelli N. Narrow excision (1-cm margin). A safe procedure for thin cutaneous melanoma. Arch Surg. 1991;126(4): $438-441$.

7. Cohn-Cedermark G, Rutqvist LE, Andersson R, et al. Long term results of a randomized study by the Swedish Melanoma Study Group on $2-\mathrm{cm}$ versus $5-\mathrm{cm}$ resection margins for patients with cutaneous melanoma with a tumor thickness of 0.8-2.0 mm. Cancer. 2000; 89(7):1495-1501.

8. Khayat D, Rixe O, Martin G, et al. Surgical margins in cutaneous melanoma ( $2 \mathrm{~cm}$ versus $5 \mathrm{~cm}$ for lesions measuring less than $2.1-\mathrm{mm}$ thick). Cancer. 2003;97(8):1941-1946.

9. Thomas JM, Newton-Bishop J, A'Hern R, et al. Excision margins in high-risk malignant melanoma. $N$ Engl $J$ Med. 2004;350(8): 757-766.

10. Heaton KM, Sussman JJ, Gershenwald JE, et al. Surgical margins and prognostic factors in patients with thick $(>4 \mathrm{~mm})$ primary melanoma. Ann Surg Oncol. 1998;5(4):322-328.

11. Coit DG, Andtbacka R, Bichakjian CK, et al. Melanoma. J Natl Compr Canc Netw. 2009;7(3):250-275.

12. Balch CM, Gershenwald JE, Soong S, et al. Final Version of 2009 AJCC Melanoma Staging and Classification. J Clin Oncol. 2009. Available at: http://www.ncbi.nlm.nih.gov/pubmed/19917835 [Accessed Nov 23, 2009].

13. Kirkwood JM, Manola J, Ibrahim J, et al. A pooled analysis of eastern cooperative oncology group and intergroup trials of adjuvant high-dose interferon for melanoma. Clin Cancer Res. 2004;10(5): 1670-1677.

14. Eggermont A, Suciu S, Testori A, Patel P, Spatz A. Ulceration of primary melanoma and responsiveness to adjuvant interferon therapy: Analysis of the adjuvant trials EORTC18952 and EORTC18991 in 2,644 patients. J Clin Oncol. 2009;27(15s):Suppl; abstr 9007.

15. Lens MB, Dawes M, Newton-Bishop JA, Goodacre T. Tumour thickness as a predictor of occult lymph node metastases in patients with stage I and II melanoma undergoing sentinel lymph node biopsy. Br J Surg. 2002;89(10):1223-1227.

16. Warycha MA, Zakrzewski J, Ni Q, et al. Meta-analysis of sentinel lymph node positivity in thin melanoma $(\leq 1 \mathrm{~mm})$. Cancer. 2009;115(4):869-879.

17. McMasters KM, Wong SL, Edwards MJ, et al. Factors that predict the presence of sentinel lymph node metastasis in patients with melanoma. Surgery. 2001;130(2):151-156.

18. Morton DL, Wen DR, Wong JH, et al. Technical details of intraoperative lymphatic mapping for early stage melanoma. Arch Surg. 1992;127(4):392-399.
19. Reintgen D, Cruse CW, Wells K, et al. The orderly progression of melanoma nodal metastases. Ann Surg. 1994;220(6):759-767.

20. Wrightson WR, Wong SL, Edwards MJ, et al. Complications associated with sentinel lymph node biopsy for melanoma. Ann Surg Oncol. 2003;10(6):676-680.

21. Morton DL, Thompson JF, Cochran AJ, et al. Sentinel-Node Biopsy or Nodal Observation in Melanoma. N Engl J Med. 2006;355(13):1307-1317.

22. van Akkooi A, Rutkowski P, van der Ploeg I, et al. Long-term follow-up of patients with minimal sentinel node tumor burden $(<0.1 \mathrm{~mm})$ according to Rotterdam criteria: A study of the EORTC Melanoma Group. $J$ Clin Oncol. 2009;27(15s):Suppl; abstr 9005.

23. Veronesi U, Adamus J, Bandiera DC, et al. Delayed regional lymph node dissection in stage I melanoma of the skin of the lower extremities. Cancer. 1982;49(11):2420-2430.

24. Sim FH, Taylor WF, Pritchard DJ, Soule EH. Lymphadenectomy in the management of stage I malignant melanoma: a prospective randomized study. Mayo Clin Proc. 1986;61(9):697-705.

25. Balch CM, Soong SJ, Bartolucci AA, et al. Efficacy of an elective regional lymph node dissection of 1 to $4 \mathrm{~mm}$ thick melanomas for patients 60 years of age and younger. Ann Surg. 1996;224(3):255-263; discussion 263-266.

26. Balch CM, Soong S, Ross MI, et al. Long-term results of a multiinstitutional randomized trial comparing prognostic factors and surgical results for intermediate thickness melanomas (1.0 to $4.0 \mathrm{~mm})$. Intergroup Melanoma Surgical Trial. Ann Surg Oncol. 2000;7(2): 87-97.

27. Cascinelli N, Morabito A, Santinami M, MacKie RM, Belli F. Immediate or delayed dissection of regional nodes in patients with melanoma of the trunk: a randomised trial. WHO Melanoma Programme. Lancet. 1998;351(9105):793-796.

28. Aloia TA, Gershenwald JE, Andtbacka RH, et al. Utility of computed tomography and magnetic resonance imaging staging before completion lymphadenectomy in patients with sentinel lymph node-positive melanoma. J Clin Oncol. 2006;24(18):2858-2865.

29. Gold JS, Jaques DP, Busam KJ, Brady MS, Coit DG. Yield and predictors of radiologic studies for identifying distant metastases in melanoma patients with a positive sentinel lymph node biopsy. Ann Surg Oncol. 2007;14(7):2133-2140.

30. Miranda EP, Gertner M, Wall J, et al. Routine imaging of asymptomatic melanoma patients with metastasis to sentinel lymph nodes rarely identifies systemic disease. Arch Surg. 2004;139(8):831-836; discussion 836-837.

31. NCCN Melanoma Guidelines. Available at: http://www.ncen.org/professionals/physician_gls/PDF/melanoma.pdf [Accessed Nov 30, 2009].

32. Buzaid AC, Tinoco L, Ross MI, Legha SS, Benjamin RS. Role of computed tomography in the staging of patients with local-regional metastases of melanoma. J Clin Oncol. 1995;13(8):2104-2108.

33. Johnson TM, Fader DJ, Chang AE, et al. Computed tomography in staging of patients with melanoma metastatic to the regional nodes. Ann Surg Oncol. 1997;4(5):396-402.

34. Kuvshinoff BW, Kurtz C, Coit DG. Computed tomography in evaluation of patients with stage III melanoma. Ann Surg Oncol. 1997;4(3):252-258.

35. Wang TS, Johnson TM, Cascade PN, et al. Evaluation of staging chest radiographs and serum lactate dehydrogenase for localized melanoma. J Am Acad Dermatol. 2004;51(3):399-405.

36. Yancovitz M, Finelt N, Warycha MA, et al. Role of radiologic imaging at the time of initial diagnosis of stage T1b-T3b melanoma. Cancer. 2007;110(5):1107-1114.

37. Henderson M, Burmeister B, Thompson J, et al. Adjuvant radiotherapy and regional lymph node field control in melanoma patients after lymphadenectomy: Results of an intergroup randomized trial (ANZMTG 01.02/TROG 02.01). J Clin Oncol (Meeting Abstracts). 2009;27(18s):Suppl; abstr LBA9084.

38. Kirkwood JM, Ibrahim JG, Sondak VK, et al. High- and lowdose interferon alfa-2b in high-risk melanoma: first analysis of intergroup trial E1690/S9111/C9190. J Clin Oncol. 2000;18(12): 2444-2458. 
39. Eggermont AMM, Suciu S, MacKie R, et al. Post-surgery adjuvant therapy with intermediate doses of interferon alfa $2 b$ versus observation in patients with stage IIb/III melanoma (EORTC 18952): randomised controlled trial. Lancet. 2005;366(9492): $1189-1196$

40. Pehamberger H, Soyer HP, Steiner A, et al. Adjuvant interferon alfa-2a treatment in resected primary stage II cutaneous melanoma. Austrian Malignant Melanoma Cooperative Group. J Clin Oncol. 1998;16(4):1425-1429.

41. Grob JJ, Dreno B, de la Salmonière $P$, et al. Randomised trial of interferon alpha-2a as adjuvant therapy in resected primary melanoma thicker than $1.5 \mathrm{~mm}$ without clinically detectable node metastases. French Cooperative Group on Melanoma. Lancet. 1998;351(9120): 1905-1910.

42. Kirkwood JM, Ibrahim JG, Sondak VK, et al. High- and lowdose interferon alfa- $2 \mathrm{~b}$ in high-risk melanoma: first analysis of intergroup trial E1690/S9111/C9190. J Clin Oncol. 2000;18(12): 2444-2458.

43. Pectasides D, Dafni U, Bafaloukos D, et al. Randomized phase III study of 1 month versus 1 year of adjuvant high-dose interferon alfa-2b in patients with resected high-risk melanoma. J Clin Oncol. 2009;27(6):939-944.

44. Phase III randomized adjuvant study of high-dose interferon alfa- $2 b$ therapy in patients with stage II or III melanoma. Available at: http:// www.cancer.gov/clinicaltrials/ECOG-1697 [Accessed Dec 1, 2009].

45. Eggermont AMM, Suciu S, Santinami M, et al. Adjuvant therapy with pegylated interferon alfa- $2 \mathrm{~b}$ versus observation alone in resected stage III melanoma: final results of EORTC 18991, a randomised phase III trial. Lancet. 2008;372(9633):117-126.

46. Young JW, Szabolcs P, Moore MA. Identification of dendritic cell colony-forming units among normal human $\mathrm{CD} 34^{+}$bone marrow progenitors that are expanded by c-kit-ligand and yield pure dendritic cell colonies in the presence of granulocyte/macrophage colonystimulating factor and tumor necrosis factor alpha. J Exp Med. 1995; 182(4):1111-1119.

47. Szabolcs P, Moore MA, Young JW. Expansion of immunostimulatory dendritic cells among the myeloid progeny of human CD34 $4^{+}$ bone marrow precursors cultured with c-kit ligand, granulocytemacrophage colony-stimulating factor, and TNF-alpha. J Immunol. 1995;154(11):5851-5861.

48. Grabstein KH, Urdal DL, Tushinski RJ, et al. Induction of macrophage tumoricidal activity by granulocyte-macrophage colony-stimulating factor. Science. 1986;232(4749):506-508.

49. Thomassen MJ, Barna BP, Rankin D, Wiedemann HP, Ahmad M. Differential effect of recombinant granulocyte macrophage colony-stimulating factor on human monocytes and alveolar macrophages. Cancer Res. 1989;49(15):4086-4089.

50. Spitler LE, Weber RW, Allen RE, et al. Recombinant human granulocyte-macrophage colony-stimulating factor (GM-CSF, sargramostim) administered for 3 years as adjuvant therapy of stages II(T4), III, and IV melanoma. J Immunother. 2009;32(6): 632-637.

51. Daud AI, Mirza N, Lenox B, et al. Phenotypic and functional analysis of dendritic cells and clinical outcome in patients with high-risk melanoma treated with adjuvant granulocyte macrophage colony-stimulating factor. J Clin Oncol. 2008;26(19):3235-3241.

52. Lawson D, Lee S, Kirkwood J, et al. E4697. Randomized, placebocontrolled phase III trial of yeast derived GM-CSF vs peptide vaccination vs GM-CSF + peptide vaccination vs placebo in patients with no evidence of disease after resection of locally advanced and/or stage IV melanoma. Data Analysis as of Sep 15, 2009. Baltimore, MD. Eastern Cooperative Oncology Group Meeting. 2009.

53. Lawson D. ECOG trial E4697 preliminary results, personal communication.

54. Hersey P, Coates AS, McCarthy WH, et al. Adjuvant immunotherapy of patients with high-risk melanoma using vaccinia viral lysates of melanoma: results of a randomized trial. J Clin Oncol. 2002;20(20):4181-4190.
55. Sondak V. Melanoma vaccines: what have we learned? Available at: http://www.societymelanomaresearch.org/pdf/melanoma_vaccines.pdf [Accessed Dec 8, 2009].

56. Sondak VK, Liu P, Tuthill RJ, et al. Adjuvant immunotherapy of resected, intermediate-thickness, node-negative melanoma with an allogeneic tumor vaccine: overall results of a randomized trial of the Southwest Oncology Group. J Clin Oncol. 2002;20(8): 2058-2066.

57. Eggermont A, Suciu S, Ruka W, et al. EORTC 18961: Post-operative adjuvant ganglioside GM2-KLH21 vaccination treatment vs observation in stage II (T3-T4N0M0) melanoma: 2nd interim analysis led to an early disclosure of the results. $J$ Clin Oncol (Meeting Abstracts). 2008;26(May 20 Suppl):abstr 9004.

58. Weber J. Overcoming immunologic tolerance to melanoma: targeting CTLA-4 with ipilimumab (MDX-010). Oncologist. 2008;13 Suppl 4:16-25.

59. Weber J, Sarnaik A, Targan S, et al. Phase II trial of extended dose antiCTLA-4 antibody ipilimumab (formerly MDX-010) with a multipeptide vaccine for resected stages IIIC and IV melanoma. J Clin Oncol (Meeting Abstracts). 2009;27(15s):Suppl; abstr 9023.

60. ClinicalTrials.gov. Efficacy study of ipilimumab versus placebo to prevent recurrence after complete resection of high risk stage III melanoma Available at: http://clinicaltrials.gov/ct2/show/NCT00636168. Accessed Dec 14, 2009.

61. Kim KB, Legha SS, Gonzalez R, et al. A randomized phase III trial of biochemotherapy versus interferon-alpha- $2 \mathrm{~b}$ for adjuvant therapy in patients at high risk for melanoma recurrence. Melanoma Res. 2009; 19(1):42-49.

62. Radny P, Caroli UM, Bauer J, et al. Phase II trial of intralesional therapy with interleukin-2 in soft-tissue melanoma metastases. $\mathrm{Br} J$ Cancer. 2003;89(9):1620-1626.

63. Green DS, Bodman-Smith MD, Dalgleish AG, Fischer MD. Phase I/II study of topical imiquimod and intralesional interleukin-2 in the treatment of accessible metastases in malignant melanoma. Br J Dermatol. 2007;156(2):337-345.

64. Daud AI, DeConti RC, Andrews S, et al. Phase I trial of interleukin-12 plasmid electroporation in patients with metastatic melanoma. J Clin Oncol. 2008;26(36):5896-5903.

65. Fraker DL. Management of in-transit melanoma of the extremity with isolated limb perfusion. Curr Treat Options Oncol. 2004;5(3): 173-184.

66. Alexander HR, Fraker DL, Bartlett DL, et al. Analysis of factors influencing outcome in patients with in-transit malignant melanoma undergoing isolated limb perfusion using modern treatment parameters. J Clin Oncol. 2010;28(1):114-118.

67. Klaase JM, Kroon BB, van Geel AN, et al. Prognostic factors for tumor response and limb recurrence-free interval in patients with advanced melanoma of the limbs treated with regional isolated perfusion with melphalan. Surgery. 1994;115(1):39-45.

68. Cornett WR, McCall LM, Petersen RP, et al. Randomized multicenter trial of hyperthermic isolated limb perfusion with melphalan alone compared with melphalan plus tumor necrosis factor: American College of Surgeons Oncology Group Trial Z0020. J Clin Oncol. 2006;24(25):4196-4201.

69. Vrouenraets BC, Klaase JM, Kroon BB, et al. Long-term morbidity after regional isolated perfusion with melphalan for melanoma of the limbs. The influence of acute regional toxic reactions. Arch Surg. 1995;130(1):43-47.

70. Overgaard J, Gonzalez Gonzalez D, Hulshof MC, et al. Randomised trial of hyperthermia as adjuvant to radiotherapy for recurrent or metastatic malignant melanoma. European Society for Hyperthermic Oncology. Lancet. 1995;345(8949):540-543.

71. Overgaard J, Gonzalez Gonzalez D, Hulshof MC, et al. Hyperthermia as an adjuvant to radiation therapy of recurrent or metastatic malignant melanoma. A multicentre randomized trial by the European Society for Hyperthermic Oncology. Int J Hyperthermia. 1996;12(1):3-20. 
72. Korn EL, Liu P, Lee SJ, et al. Meta-analysis of phase II cooperative group trials in metastatic stage IV melanoma to determine progressionfree and overall survival benchmarks for future phase II trials. J Clin Oncol. 2008;26(4):527-534.

73. Herman P, Machado MAC, Montagnini AL, et al. Selected patients with metastatic melanoma may benefit from liver resection. World $J$ Surg. 2007;31(1):171-174.

74. Rose DM, Essner R, Hughes TM, et al. Surgical resection for metastatic melanoma to the liver: the John Wayne Cancer Institute and Sydney Melanoma Unit experience. Arch Surg. 2001;136(8):950-955.

75. Long-term results of lung metastasectomy: prognostic analyses based on 5206 cases. The International Registry of Lung Metastases. J Thorac Cardiovasc Surg. 1997;113(1):37-49.

76. Atkins MB, Lotze MT, Dutcher JP, et al. High-dose recombinant interleukin-2 therapy for patients with metastatic melanoma: analysis of 270 patients treated between 1985 and 1993. J Clin Oncol. 1999; 17(7):2105-2116.

77. Atkins MB, Kunkel L, Sznol M, Rosenberg SA. High-dose recombinant interleukin-2 therapy in patients with metastatic melanoma: long-term survival update. Cancer J Sci Am. 2000;6 Suppl 1:S11-S14.

78. Rosenberg SA, Yang JC, White DE, Steinberg SM. Durability of complete responses in patients with metastatic cancer treated with high-dose interleukin-2: identification of the antigens mediating response. Ann Surg. 1998;228(3):307-319.

79. Rosenberg SA, Yang JC, Topalian SL, et al. Treatment of 283 consecutive patients with metastatic melanoma or renal cell cancer using high-dose bolus interleukin-2. JAMA. 1994;271(12):907-913.

80. Royal RE, Steinberg SM, Krouse RS, et al. Correlates of response to interleukin-2 therapy in patients treated for metastatic renal cancer and melanoma. Cancer J Sci Am. 1996;2(2):91-98.

81. Schwartzentruber D, Lawson D, Richards J, et al. A phase III multi-institutional randomized study of immunization with the gp-100:209$217(210 \mathrm{M})$ peptide followed by high-dose interleukin-2 compared with high-dose interleukin-2 alone in patients with metastatic melanoma. JClin Oncol (Meeting Abstracts). 2009;27(18s):Suppl; abstr CRA9011.

82. Sosman JA, Carrillo C, Urba WJ, et al. Three phase II cytokine working group trials of gp-100 (210M) peptide plus high-dose interleukin-2 in patients with HLA-A2-positive advanced melanoma. J Clin Oncol. 2008;26(14):2292-2298

83. Leach DR, Krummel MF, Allison JP. Enhancement of antitumor immunity by CTLA-4 blockade. Science. 1996;271(5256):1734-1736.

84. Hamid O, Chin K, Li J, et al. Dose effect of ipilimumab in patients with advanced melanoma: Results from a phase II, randomized, dose-ranging study. J Clin Oncol (Meeting Abstracts). 2008;26(May 20 Suppl):abstr 9025.

85. O'Day S, Ibrahim R, DePril V, et al. Efficacy and safety of ipilimumab induction and maintenance dosing in patients with advanced melanoma who progressed on one or more prior therapies. J Clin Oncol (Meeting Abstracts). 2008;26(May 20 Suppl):abstr 9021.

86. O'Day S, Weber J, Lebbe C, et al. Effect of ipilimumab treatment on 18-month survival: Update of patients (pts) with advanced melanoma treated with $10 \mathrm{mg} / \mathrm{kg}$ ipilimumab in three phase II clinical trials. J Clin Oncol (Meeting Abstracts). 2009;27(15s):Suppl; abstr 9033.

87. Attia P, Phan GQ, Maker AV, et al. Autoimmunity correlates with tumor regression in patients with metastatic melanoma treated with anti-cytotoxic T-lymphocyte antigen-4. J Clin Oncol. 2005; 23(25):6043-6053.

88. Sanderson K, Scotland R, Lee P, et al. Autoimmunity in a phase I trial of a fully human anti-cytotoxic T-lymphocyte antigen-4 monoclonal antibody with multiple melanoma peptides and Montanide ISA 51 for patients with resected stages III and IV melanoma. J Clin Oncol. 2005;23(4):741-750.

89. Hodi F, Hoos A, Ibrahim R, et al. Novel efficacy criteria for antitumor activity to immunotherapy using the example of ipilimumab, an antiCTLA-4 monoclonal antibody. J Clin Oncol (Meeting Abstracts). 2008;26:Suppl; abstr 3008.
90. Wolchok J, Ibrahim R, DePril V, et al. Antitumor response and new lesions in advanced melanoma patients on ipilimumab treatment. J Clin Oncol (Meeting Abstracts). 2008;26(May 20 Suppl):May 20 Suppl; abstr 3020 .

91. Downey SG, Klapper JA, Smith FO, et al. Prognostic factors related to clinical response in patients with metastatic melanoma treated by CTLassociated antigen-4 blockade. Clin Cancer Res. 2007;13(22 Pt 1): 6681-6688.

92. Hodi FS, O'Day SJ, McDermott DF, et al. Improved survival with ipilimumab in patients with metastatic melanoma. $N$ Engl J Med. 2010; Jun 14 [Epub ahead of print].

93. Fischkoff S, Hersh E, Weber J, et al. Durable responses and long-term progression-free survival observed in a phase II study of MDX-010 alone or in combination with dacarbazine (DTIC) in metastatic melanoma. J Clin Oncol (Meeting Abstracts). 2005;23(16s, part I of II (Jun 1 Supplement)):abstr 7525.

94. Hersh E, Weber J, Powderly J, et al. Disease control and long-term survival in chemotherapy-naive patients with advanced melanoma treated with ipilimumab (MDX-010) with or without dacarbazine. $J$ Clin Oncol (Meeting Abstracts). 2008;26(May 20 Suppl):abstr 9022 .

95. ClinicalTrials.gov. Dacarbazine and ipilimumab vs dacarbazine with placebo in untreated unresectable stage III or IV melanoma Available at: http://clinicaltrials.gov/ct2/show/NCT00324155. Accessed Dec 13, 2009.

96. Maker AV, Phan GQ, Attia P, et al. Tumor regression and autoimmunity in patients treated with cytotoxic $\mathrm{T}$ lymphocyte-associated antigen 4 blockade and interleukin-2: a phase I/II study. Ann Surg Oncol. 2005;12(12):1005-1016.

97. Rosenberg SA, Packard BS, Aebersold PM, et al. Use of tumor-infiltrating lymphocytes and interleukin-2 in the immunotherapy of patients with metastatic melanoma. A preliminary report. $N$ Engl J Med. 1988;319(25):1676-1680.

98. Rosenberg SA, Yannelli JR, Yang JC, et al. Treatment of patients with metastatic melanoma with autologous tumor-infiltrating lymphocytes and interleukin-2. J Natl Cancer Inst. 1994; 86(15): 1159-1166.

99. Rosenberg SA, Restifo NP, Yang JC, Morgan RA, Dudley ME. Adoptive cell transfer: a clinical path to effective cancer immunotherapy. Nat Rev Cancer. 2008;8(4):299-308.

100. Clinical Trials. Dudley ME, Yang JC, Sherry R, et al. Adoptive cell therapy for patients with metastatic melanoma: evaluation of intensive myeloablative chemoradiation preparative regimens. J Clin Oncol. 2008; 26(32):5233-5239.

101. Straten PT, Becker JC. Adoptive cell transfer in the treatment of metastatic melanoma. J Invest Dermatol. 0;129(12):2743-2745.

102. Clinical Trials. Lymphodepletion plus adoptive cell transfer with or without dendritic cell immunization. Available at: http://clinicaltrials. gov/ct2/show/NCT00338377?term=adoptive+cell+transfer+AND+m elanoma\&rank=1. Accessed Dec 14, 2009.

103. Clinical Trials. Lymphodepletion plus adoptive cell transfer with high dose interleukin-2 in patients with metastatic melanoma. Available at: http:/clinicaltrials.gov/ct2/show/NCT01005745?term=adoptive+cell +transfer+AND+melanoma\&rank=2. Accessed Dec 14, 2009.

104. Clinical Trials. Study of gene modified immune cells in patients with advanced melanoma. Available at: http://clinicaltrials.gov/ ct $2 /$ show/NCT00910650? term=adoptive+cell+transfer+AND+m elanoma\&rank=6. Accessed Dec 14, 2009.

105. Luikart SD, Kennealey GT, Kirkwood JM. Randomized phase III trial of vinblastine, bleomycin, and cis-dichlorodiammine-platinum versus dacarbazine in malignant melanoma. J Clin Oncol. 1984; 2(3):164-168.

106. Chapman PB, Einhorn LH, Meyers ML, et al. Phase III multicenter randomized trial of the Dartmouth regimen versus dacarbazine in patients with metastatic melanoma. J Clin Oncol. 1999;17(9): 2745-2751. 
107. Middleton MR, Grob JJ, Aaronson N, et al. Randomized phase III study of temozolomide versus dacarbazine in the treatment of patients with advanced metastatic malignant melanoma. J Clin Oncol. 2000;18(1):158-166.

108. Schadendorf D, Ugurel S, Schuler-Thurner B, et al. Dacarbazine (DTIC) versus vaccination with autologous peptide-pulsed dendritic cells (DC) in first-line treatment of patients with metastatic melanoma: a randomized phase III trial of the DC study group of the DeCOG. Ann Oncol. 2006;17(4):563-570.

109. Atkins M, Sosman J. Cytotoxic chemotherapy and biochemotherapy for metastatic melanoma. Available at: http://www.uptodate.com/online/ content/topic.do?topicKey=skin_can/4732\&selectedTitle $=1 \% 7 \mathrm{E} 150$ \&source=search_result [Accessed Dec 14, 2009].

110. Hill GJ, Krementz ET, Hill HZ. Dimethyl triazeno imidazole carboxamide and combination therapy for melanoma. IV. Late results after complete response to chemotherapy (Central Oncology Group protocols 7130, 7131, and 7131A). Cancer. 1984;53(6):1299-1305.

111. Eton O, Legha SS, Bedikian AY, et al. Sequential biochemotherapy versus chemotherapy for metastatic melanoma: results from a phase III randomized trial. J Clin Oncol. 2002;20(8):2045-2052.

112. Legha SS, Ring S, Papadopoulos N, et al. A prospective evaluation of a triple-drug regimen containing cisplatin, vinblastine, and dacarbazine (CVD) for metastatic melanoma. Cancer. 1989;64(10):2024-2029.

113. Paul MJ, Summers Y, Calvert AH, et al. Effect of temozolomide on central nervous system relapse in patients with advanced melanoma. Melanoma Res. 2002;12(2):175-178.

114. Einzig AI, Hochster H, Wiernik PH, et al. A phase II study of taxol in patients with malignant melanoma. Invest New Drugs. 1991;9(1): 59-64.

115. Bedikian AY, Weiss GR, Legha SS, et al. Phase II trial of docetaxel in patients with advanced cutaneous malignant melanoma previously untreated with chemotherapy. J Clin Oncol. 1995; 13(12):2895-2899.

116. Aamdal S, Wolff I, Kaplan S, et al. Docetaxel (Taxotere) in advanced malignant melanoma: a phase II study of the EORTC Early Clinical Trials Group. Eur J Cancer. 1994;30A(8):1061-1064.

117. Hauschild A, Agarwala SS, Trefzer U, et al. Results of a phase III, randomized, placebo-controlled study of sorafenib in combination with carboplatin and paclitaxel as second-line treatment in patients with unresectable stage III or stage IV melanoma. J Clin Oncol. 2009;27(17):2823-2830.

118. Glantz MJ, Choy H, Kearns CM, et al. Paclitaxel disposition in plasma and central nervous systems of humans and rats with brain tumors. J Natl Cancer Inst. 1995;87(14):1077-1081.

119. Fojo T, Menefee M. Mechanisms of multidrug resistance: the potential role of microtubule-stabilizing agents. Ann Oncol. 2007;18 Suppl 5:v3-v8

120. Klar U, Buchmann B, Schwede W, et al. Total synthesis and antitumor activity of ZK-EPO: the first fully synthetic epothilone in clinical development. Angew Chem Int Ed Engl. 2006;45(47): 7942-7948.

121. Hoffmann J, Vitale I, Buchmann B, et al. Improved cellular pharmacokinetics and pharmacodynamics underlie the wide anticancer activity of sagopilone. Cancer Res. 2008;68(13): 5301-5308.

122. Hoffmann J, Fichtner I, Lemm M, et al. Sagopilone crosses the blood-brain barrier in vivo to inhibit brain tumor growth and metastases. Neuro-oncology. 2009;11(2):158-166.

123. Silvani A, Gaviani P, Fiumani A, et al. Systemic sagopilone (ZK-EPO) treatment of patients with recurrent malignant gliomas. J Neurooncol. 2009. Available at: http://www.ncbi.nlm.nih.gov/pubmed/19381446 [Accessed Jul 22, 2009].

124. Stupp R, Tosoni A, Taal W, et al. A phase II multicenter trial of sagopilone in patients with recurrent glioblastoma. Journal of Clinical Oncology. 2008;26:Abstract 2015.
125. ASCO. Phase II trial of sagopilone (ZK-EPO), a novel synthetic epothilone, with significant activity in metastatic melanoma. Available at: http://www.asco.org/ASCOv2/Meetings/Abstracts?\&vmview=abst_ detail_view\&confID=65\&abstractID=30552. Accessed Jul 22, 2009.

126. Bajetta E, Del Vecchio M, Nova P, et al. Multicenter phase III randomized trial of polychemotherapy (CVD regimen) versus the same chemotherapy (CT) plus subcutaneous interleukin-2 and interferon-alpha2b in metastatic melanoma. Ann Oncol. 2006;17(4): 571-577.

127. Atkins MB, Hsu J, Lee S, et al. Phase III trial comparing concurrent biochemotherapy with cisplatin, vinblastine, dacarbazine, interleukin-2, and interferon alfa-2b with cisplatin, vinblastine, and dacarbazine alone in patients with metastatic malignant melanoma (E3695): a trial coordinated by the Eastern Cooperative Oncology Group. J Clin Oncol. 2008;26(35):5748-5754.

128. Ives NJ, Stowe RL, Lorigan P, Wheatley K. Chemotherapy compared with biochemotherapy for the treatment of metastatic melanoma: a meta-analysis of 18 trials involving 2,621 patients. J Clin Oncol. 2007;25(34):5426-5434.

129. O'Day SJ, Atkins MB, Boasberg P, et al. Phase II multicenter trial of maintenance biotherapy after induction concurrent biochemotherapy for patients with metastatic melanoma. J Clin Oncol. 2009;27(36):6207-6212.

130. Smalley KSM, Herlyn M. Targeting intracellular signaling pathways as a novel strategy in melanoma therapeutics. Ann NY Acad Sci. 2005; 1059:16-25.

131. Spofford LS, Abel EV, Boisvert-Adamo K, Aplin AE. Cyclin D3 expression in melanoma cells is regulated by adhesion-dependent phosphatidylinositol 3-kinase signaling and contributes to G1-S progression. J Biol Chem. 2006;281(35):25644-25651.

132. Beadling C, Jacobson-Dunlop E, Hodi FS, et al. KIT gene mutations and copy number in melanoma subtypes. Clin Cancer Res. 2008; 14(21):6821-6828.

133. Wilhelm SM, Adnane L, Newell P, et al. Preclinical overview of sorafenib, a multikinase inhibitor that targets both Raf and VEGF and PDGF receptor tyrosine kinase signaling. Mol Cancer Ther. 2008; 7(10):3129-3140.

134. Flaherty K, Puzanov I, Sosman J, et al. Phase I study of PLX4032: Proof of concept for V600E BRAF mutation as a therapeutic target in human cancer. J Clin Oncol. 2009;27(15s (Supplement; abstract 9000)).

135. Puzanov I, Nathanson K, Chapman P, et al. PLX4032, a highly selective V600E BRAF kinase inhibitor: Clinical correlation of activity with pharmacokinetic and pharmacodynamic parameters in a phase I trial. J Clin Oncol (Meeting Abstracts). 2009;27(15s):Suppl; abstr 9021.

136. ClinicalTrials.gov. A Study of RO5185426 in previously treated patients with metastatic melanoma. Available at: http://www. clinicaltrials.gov/ct2/show/NCT00949702?term $=$ plx-4032\& rank=2 [Accessed Dec 14, 2009].

137. Clinical Trials.gov. A study of RO5185426 in comparison with dacarbazine in previously untreated patients with metastatic melanoma. Available at: http://www.clinicaltrials.gov/ct2/show/ NCT01006980?term=RO5185426\&rank=3 [Accessed Dec 14, 2009].

138. Wyman K, Atkins MB, Prieto V, et al. Multicenter Phase II trial of high-dose imatinib mesylate in metastatic melanoma: significant toxicity with no clinical efficacy. Cancer. 2006;106(9):2005-2011.

139. Carvajal R, Chapman P, Wolchok J, et al. A phase II study of imatinib mesylate (IM) for patients with advanced melanoma harboring somatic alterations of KIT. J Clin Oncol (Meeting Abstracts). 2009;27(15s):Suppl; abstr 9001.

140. Zhu Y, Si L, Kong Y, et al. Response to sunitinib in Chinese KIT-mutated metastatic mucosal melanoma. J Clin Oncol (Meeting Abstracts). 2009;27(Suppl):Suppl abstr e20017.

141. Woodman S, Trent J, Stemke-Hale K, et al. Selective activity of dasatinib for the most common KIT mutation in melanoma (L576P). J Clin Oncol (Meeting Abstracts). 2009;27(15s):Suppl; abstr 9019. 
142. Clinical Trials. A study of AMNN107 against dacarbazine (DTIC) in the treatment of metastatic and/or inoperable melanoma harboring a c-Kit mutation. Available at: http://www.clinicaltrials.gov/ct2/show/NC T01028222?term $=k i t+m e l a n o m a \& r a n k=1$ [Accessed Dec 14, 2009].

143. Clinical Trials. Clinical trial of sutent to treat metastatic melanoma Available at: http://www.clinicaltrials.gov/ct2/show/NCT00631618? term=kit+melanoma\&rank=2. Accessed Dec 14, 2009.

144. Clinical Trials. Imatinib mesylate in treating patients with stage III or stage IV melanoma that cannot be removed by surgery. Available at: http://www.clinicaltrials.gov/ct2/show/NCT00470470?term=kit+mel anoma\&rank=3. Accessed Dec 14, 2009.

145. Clinical Trials. Imatinib in patients with mucosal or acral/lentiginous melanoma. Available at: http://www.clinicaltrials.gov/ ct $2 /$ show/NCT00424515?term=kit+melanoma\&rank=4. Accessed Dec 14, 2009.

146. Clinical Trials. Trial of imatinib $\left(\right.$ Gleevec $\left.^{\circledR}\right)$ in selected patients with metastatic melanoma. Available at: http://www.clinicaltrials.gov/ct2/ show/NCT00881049?term=kit+melanoma\&rank=5. Accessed Dec 14, 2009.

147. Clinical Trials. SU011248 in patients with metastatic mucosal or acral/ lentiginous melanoma. Available at: http://www.clinicaltrials.gov/ct2/ show/NCT00577382?term=kit+melanoma\&rank=6. Accessed Dec 14, 2009.
148. Fife KM, Colman MH, Stevens GN, et al. Determinants of outcome in melanoma patients with cerebral metastases. J Clin Oncol. 2004; 22(7):1293-1300.

149. Mori Y, Kondziolka D, Flickinger JC, et al. Stereotactic radiosurgery for cerebral metastatic melanoma: factors affecting local disease control and survival. Int J Radiat Oncol Biol Phys. 1998;42(3):581-589.

150. Yu C, Chen JCT, Apuzzo MLJ, et al. Metastatic melanoma to the brain: prognostic factors after gamma knife radiosurgery. Int J Radiat Oncol Biol Phys. 2002;52(5):1277-1287.

151. Selek U, Chang EL, Hassenbusch SJ, et al. Stereotactic radiosurgical treatment in 103 patients for 153 cerebral melanoma metastases. Int J Radiat Oncol Biol Phys. 2004;59(4):1097-1106.

152. Radbill AE, Fiveash JF, Falkenberg ET, et al. Initial treatment of melanoma brain metastases using gamma knife radiosurgery: an evaluation of efficacy and toxicity. Cancer. 2004;101(4):825-833.

153. Stone A, Cooper J, Koenig KL, Golfinos JG, Oratz R. A comparison of survival rates for treatment of melanoma metastatic to the brain. Cancer Invest. 2004;22(4):492-497.
Cancer Management and Research

\section{Publish your work in this journal}

Cancer Management and Research is an international, peer-reviewed open access journal focusing on cancer research and the optimal use of preventative and integrated treatment interventions to achieve improved outcomes, enhanced survival and quality of life for the cancer patient The journal welcomes original research, clinical \& epidemiological

\section{Dovepress}

studies, reviews \& evaluations, guidelines, expert opinion \& commentary, case reports \& extended reports. The manuscript management system is completely online and includes a very quick and fair peerreview system, which is all easy to use. Visit http://www.dovepress.com/ testimonials.php to read real quotes from published authors. 